\title{
The Effect of Intramuscular Administration of Dexamethasone Alone or in Combination with Hyoscine Butylbromide in Shortening the duration of Induced Labor in Primigravidas
}

\author{
OMNEYA HELAL, M.D.; MOUTAZ EL-SHERBINI, M.D. and SHERIF S. ZAKI, M.D. \\ The Department of Obstetrics and Gynecology, Faculty of Medicine, Cairo University, Egypt
}

\begin{abstract}
Background: Induction of labour is common in clinical practice and is usually troublesome in primigravidas. Obestatricians are always in search of the best method of induction to ensure the best maternal and fetal outcome.
\end{abstract}

Aim of Study: To evaluate the effect of Intramuscular (IM) administration of dexamethasone alone or in combined with Hyoscine Butylbromide (HBB) on the duration of labour induction in primigravidas.

Patients and Methods: A randomized controlled study was conducted at the Obstetrics and Gynecology casualty department at Kasr Al-Ainy Hospital (Cairo University, Egypt) in the period from November 2015 to April 2016. 150 primigravidas with a singleton living healthy fetus who underwent Induction of Labour (IOL) participated in the study. They were randomly allocated into 3 groups: Group A where 50 women received IM dexamethasone ( $8 \mathrm{mg}) 6$ hours prior to induction then IM $2 \mathrm{ml}$ saline at the onset of the active phase, Group B where 50 women received IM dexamethasone $(8 \mathrm{mg})$ 6 hours prior to induction then IM HBB (40mg) at the onset of the active phase and Group C (control) where 50 women received two IM saline injections $(2 \mathrm{~mL}) 6$ hours prior to induction and at the onset of the active phase. IOL was done using $2.5 \mathrm{mIU} / \mathrm{min}$ intravenous drip of oxytocin (in $500 \mathrm{~mL}$ lactated Ringer's solution), increasing the dose by $2.5 \mathrm{mIU} / \mathrm{ml}$ every 20 minutes until labour started. Amniotomy was done at a cervical dilatation of $\geq 6 \mathrm{~cm}$, if spontaneous rupture of the membranes had not spontaneously occurred. All participants were monitored by a partogram and continuous CTG throughout labor.

Results: Both groups A and B showed significant shortening of the duration of the latent phase $(3.4 \pm 0.6$ and $3.6 \pm 0.7$ vs $4.5 \pm 0.6 \mathrm{hrs})$, the duration of the active phase ( $3.7 \pm 0.7$ and $3.7 \pm 0.6$ vs. $4.8 \pm 0.7 \mathrm{hrs})$, the duration of the $2 \mathrm{nd}$ stage (21.6 \pm 5.3 and $21.9 \pm 7.2$ vs. $30.0 \pm 5.3$ minutes) as well as the duration of the stage $(6.3 \pm 1.7$ and $7.5 \pm 1.9$ vs. $10.0 \pm 2.8$ minutes $)$ respectively when compared to the control group ( $p$-value $<0.001$ for all). No statistical significant differences were noticed in neonatal Apgar score at 1 and 5 minutes between the three groups.

Correspondence to: Dr. Omneya Helal, E-Mail: dromneya@hotmail.com
Conclusions: Intramuscular injection of dexamethasone alone or in addition to hyoscine butylbromide was found to shorten the duration of induced labour in primigravidas, with no observed maternal or neonatal complications.

Key Words: Dexamethasone - Hyoscine - Induction of labour.

\section{Introduction}

INDUCTION of labor is the initiation of uterine contractions before the onset of spontaneous labor regardless the state of membranes. Its overall incidence is about $9.6 \%$ and in the united states, it was increased from 9.6 to $23.2 \%$ during the years from 1991 to 2011 [1]

Labor is induced when the benefits of termination of pregnancy to the mother and/or the fetus outweigh its continuation. Indications for induction include rupture of membrane without labor pains, oligohydramnios, non reassuring fetal evaluation, postdates and medical diseases [2] .

Prolonged labor puts a great strain on both the mother and the fetus. Hence, shortening its duration will decrease maternal and fetal compromises during labor. The main determinants of the duration of labor are uterine contractions and rate of cervical dilatation. The use of oxytocin and prostaglandins has been solidly documented in augmentation of labor [3].

Corticosteroids have been tried for labor induction. It has been postulated as one of the methods suggested for cervical ripening and labor acceleration especially after documentation of glucocorticoid receptors on the fetal amnion. Both placental and fetal adrenal cortisol play a role in this process. Fetal glucocorticoids inhance prostaglandin synthesis through both direct and indirect action through activation of cyclooxygenase enzyme [4] . 
Corticotropin Releasing Hormone (CRH) levels in the fetus rise during the third trimester of pregnancy [5]. Steroids from fetal adrenals are produced in considerable amounts in the $3^{\text {rd }}$ trimester, leading to a rise in fetal levels of cortisol and DHEAS (dehydroepiandrosterone sulfate). This results in modification of the uterine contractility with more prostaglandins production from fetal membranes, more corticosteroids and increased estrogen levels. This will result in an altered estrogen to progesterone ratio an enhanced expression of contractile proteins [6].

Corticosteroids were used either extra-amniotic or intravenous and both methods have proved successful $[\mathbf{7 , 8}]$.

Hyoscine Butylbromide (HBB), a parasympatholytic, is an effective antispasmodic drug that has a peripheral anticholinergic action. It doesn't cross the Blood Brain Barrier (BBB), so it has no central action. It relieves the spasms in the smooth muscles including that of the female genital tract, thus enhancing dilatation of the cervix $[9,10]$

Hyoscine butylbromide is effective in the acceleration of cervical ripening and thus in shortening the duration of labor. It inhibits the muscarinic effects of acetylcholine on structures innervated by cholinergic nerves and on the smooth muscles responding to acetyl choline but lacking cholinergic innervations [11]. It was claimed to reduce the duration of the first stage of labour by overcoming cervical spasm and enhancing dilatation of the cervix [12]

\section{Patients and Methods}

This prospective randomized single-blinded placebo-controlled study was conducted at the Obstetrics and Gynecology causality unit of Kasr Al-Ainy Medical School (Cairo University), in the period from November 2015 to April 2016. The study was approved by the Hospital Ethics Committee and was registered under the following no (ACTRN12616000208404). An informed consents were obtained from all participants after explanation of the whole trial risks and benefits. The study was not supported by any pharmacological company.

150 primigravidas with a singleton living healthy fetus who underwent Induction of Labor (IOL) were enrolled in the study. IOL was indicated if Gestational Age (GA) was 40-41wks or with a suspected foetal compromise (e.g. diminished daily foetal movement count or abnormal foetal surveillance tests) at 38-41 weeks of gestational age. They were randomized into three groups: Group A in which 50 women received IM dexamethasone (8mg) 6 hours before IOL then IM $2 \mathrm{ml}$ saline at the beginning of active phase, Group B in which 50 women received IM dexamethasone $(8 \mathrm{mg}) 6$ hours before IOL then IM HBB (40mg) with the beginning of the active phase and Group $\mathrm{C}$ (control group) in which 50 women received two IM saline injections $(2 \mathrm{~mL}) 6$ hours before IOL and at the beginning of the active phase. Randomization was done using computer-generated random numbers.

Inclusion criteria were: Maternal age between $18 \& 35$ years old, gestational age 38 to 41 weeks (confirmed by a reliable date of the last menstrual period and 1 st trimesteric ultrasound scan), vertex presentation of the fetus, favorable cervix (Bishop Score 27$)$ \& intact membranes.

Exclusion criteria were: Chronic or pregnancy induced diseases, any contraindication to vaginal delivery (e.g. mal-presentation, contracted pelvis or placenta previa), maternal use of drugs (apart from nutritional supplementation), abnormal vaginal bleeding upon pelvic examination, abnormal fetal growth (IUGR or macrosomia), non-reassuring initial fetal CTG, presence of regular uterine contractions (3/10mins), uterine scar or anomalies, oligohydramnios (AFI $<5$ th percentile) or the use of epidural analgesia.

For all patients, full history was taken followed by complete physical examination (including Bishop score assessment) and obstetric ultrasound. Initial baseline CTG was done to confirm fetal well-being. Patients were then randomized into one of the three groups and accordingly were given either $2 \mathrm{ml}$ dexamethasone (8mg IM) in Group A or B or $2 \mathrm{ml}$ saline IM in Group C 6 hours later, IOL was commenced using the following protocol; $2.5 \mathrm{mIU} / \mathrm{min}$ of oxytocin intravenous drip (in 500 $\mathrm{mL}$ lactated Ringer's solution), with the dose increased by $2.5 \mathrm{mIU} / \mathrm{ml}$ every 20 minutes until labor was established (defined as the presence of at least three forceful uterine contraction over a 10-minute span, associated with progressive cervical effacement and dilatation).

No cervical ripening agents were used before IOL in the three groups. With the beginning of the active phase (defined as the presence of at least three regular uterine contraction over 10 minutes with effaced cervix not less than $50 \%$ with $3-4 \mathrm{~cm}$ dilatation), patients in Group B received $2 \mathrm{ml} \mathrm{HBB}$ while those in Groups $A$ and $C$ received $2 \mathrm{ml}$ saline.

Participants were monitored together with fetal well-being surveillance using continuous CTG monitoring. A partogram was maintained through- 
out labor and vaginal examinations were conducted and recorded every 2 hours. Amniotomy was done at cervical dilatation $\geq 6 \mathrm{~cm}$ if spontaneous rupture of membranes had not occurred. Opioid analgesia was given after amniotomy (meperidine hydrochloride 50 to $100 \mathrm{mg} \mathrm{IM}$ at intervals of 2 to $4 \mathrm{hrs}$ ).

Primary outcomes included recording and comparing the duration of the latent phase, active phase and the second and third stages of labour in the three groups. Secondary outcomes included the mode of delivery, maternal complications, and neonatal Apgar score at 1 and 5mins after birth. The study included a consecutive sample of all primigravidas in need of induction who presented to the authers during the study period. The power of the study was calculated based on the main primary outcome measure (duration of latent phase) and it was found to be $94 \%$ based on an effect size of 0.34 using ANOVA test.

Continuous data were expressed as mean \pm SD and were compared using ANOVA test, then postHoc" schefe test" was used for pairwise comparison. Categorical data were expressed as number percentages and were compared using the Fisher exact test. A $p$-value $<0.05$ was considered statistically significant. Data analysis was performed using the Statistical Package for the Social Sciences program, V20.0 (SPSS Inc., Chicago, IL, USA).

\section{Results}

We recruited 257 patients and excluded 107 who either did not fill the inclusion criteria or refused to join the study. Finally, a total of 150 eligible women were randomized into three equal groups. Analysis included 128 patients Fig. (1). There were no statistically significant differences between the three groups regarding maternal age, gestational age, body mass index, Bishop scoring or the neonatal birth weight (Table 1).

Both Groups A and B showed significant shortening of the time from induction of labor to the active phase (latent period), the duration of the active phase of labor, the duration of the 2 nd stage as well as the duration of the ${ }^{3 \text { rd }}$ stage in comparison to the control group ( $p$-value $<0.001$ for all). In addition, combination therapy in Group B caused further shortening of the third stage of labor compared to the dexamethasone alone in Group A $(p=0.043)$. No statistical significant differences were noticed between the Apgar score at 1 and 5 minutes after birth in the 3 groups (Table 2).

There was no significant difference in the rate of cesarean section between the groups $(10 \%$ vs. $14 \%$ vs. $20 \% ; p=0.363)$. The most common indications for cesarean section in the 3 groups are shown in (Table 4). There were no instrumental vaginal deliveries.

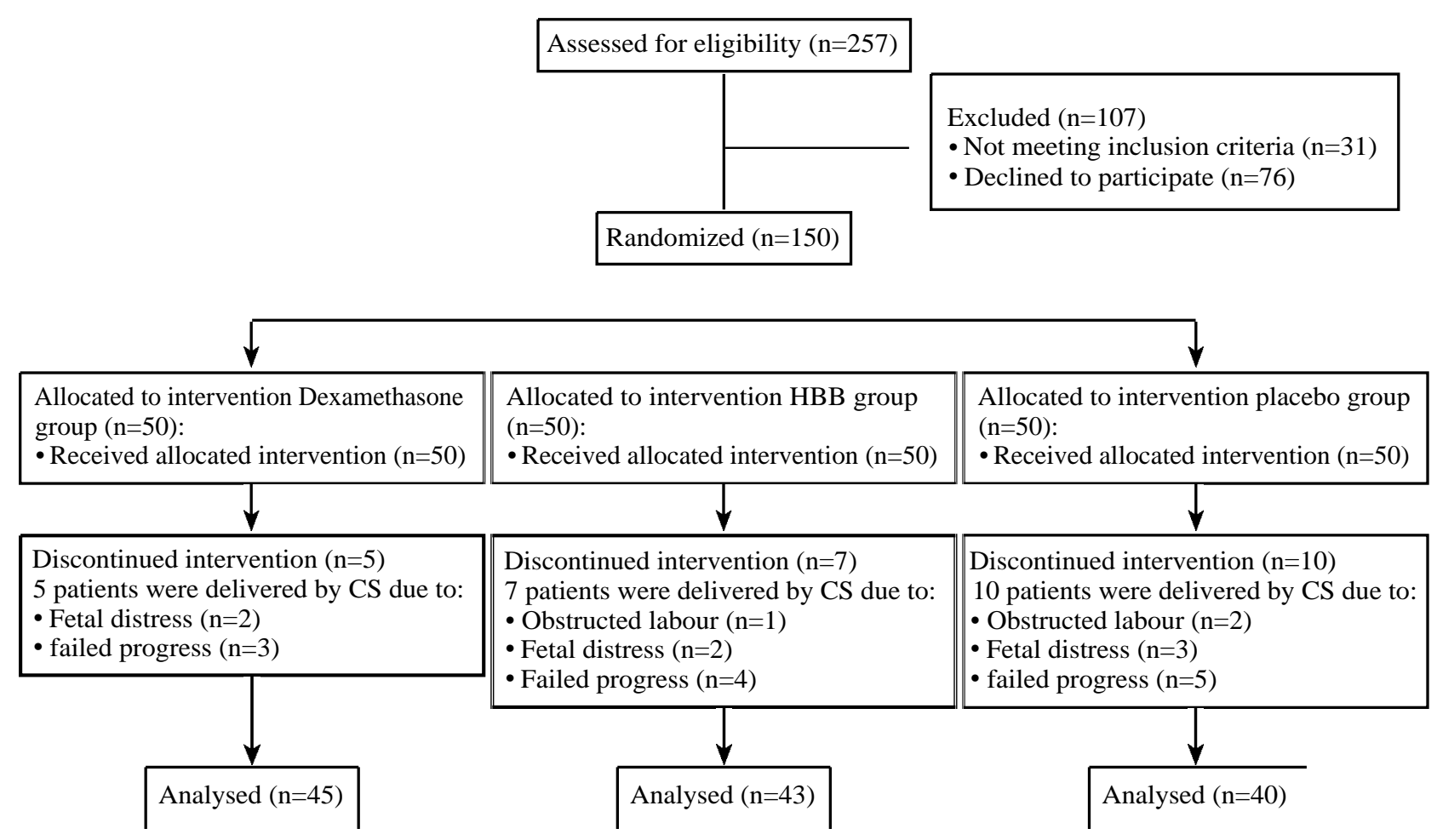

Fig. (1): Consort flow of patients through the study. 
Table (1): Baseline characteristics of the study population.

\begin{tabular}{lllll}
\hline & $\begin{array}{c}\text { Group A } \\
(\mathrm{n}-45)\end{array}$ & $\begin{array}{c}\text { Group B } \\
(\mathrm{n}=43)\end{array}$ & $\begin{array}{c}\text { Group C } \\
(\mathrm{n}=40)\end{array}$ & $p<$ \\
\hline Age (yrs) & $27.3 \pm 3.8$ & $27.4 \pm 3.6$ & $27.1 \pm 4.3$ & 0.936 \\
BMI & $28.9 \pm 2.6$ & $29.1 \pm 2.2$ & $29.8 \pm 2.9$ & 0.152 \\
GA (wks) & $39.5 \pm 1.0$ & $39.8 \pm 0.9$ & $39.9 \pm 0.9$ & 0.079 \\
Bischop score & $7.8 \pm 0.8$ & $7.8 \pm 0.8$ & $7.7 \pm 0.8$ & 0.676 \\
Birth wt (gm) & $3292.4 \pm 227.3$ & $3261.0 \pm 183.6$ & $3290.5 \pm 206.9$ & 0.696 \\
\hline
\end{tabular}

BMI : Body Mass Index.

GA : Gestational Age.

Table (2): Comparison of duration of stages of labor and Apgar score in the study group.

\begin{tabular}{lllll}
\hline & $\begin{array}{c}\text { Group A } \\
(\mathrm{n}=50)\end{array}$ & $\begin{array}{c}\text { Group B } \\
(\mathrm{n}=50)\end{array}$ & $\begin{array}{c}\text { Group C } \\
(\mathrm{n}=50)\end{array}$ & $p<$ \\
\hline Latent phase (hrs) & $3.42 \pm 0.67$ & $3.56 \pm 0.64$ & $4.48 \pm 0.66$ & 0.001 \\
Active phase (hrs) & $3.71 \pm 0.70$ & $3.68 \pm 0.62$ & $4.75 \pm 0.72$ & 0.001 \\
2nd stage (min) & $21.6 \pm 5.3$ & $21.9 \pm 7.2$ & $30.0 \pm 5.3$ & 0.001 \\
3rd stage (min) & $6.3 \pm 1.7$ & $7.5 \pm 1.9$ & $10.0 \pm 2.8$ & 0.001 \\
Apgare score 1min & $6.1 \pm 1.2$ & $6.6 \pm 1.0$ & $6.5 \pm 0.9$ & 0.063 \\
Apgare score 5min & $9.0 \pm 0.8$ & $9.1 \pm 0.8$ & $8.8 \pm 0.7$ & 0.166 \\
\hline
\end{tabular}

$p$-value $<0.05$ is considered significant.

Table (3): Mode of delivery of the three groups.

\begin{tabular}{lllll}
\hline Mode of delivery & $\begin{array}{c}\text { Group I } \\
(\mathrm{n}=50)\end{array}$ & $\begin{array}{c}\text { Group } \\
(\mathrm{n}=50)\end{array}$ & $\begin{array}{c}\text { Control group } \\
(\mathrm{n}=50)\end{array}$ & Total \\
\hline $\begin{array}{l}\text { Vaginal: } \\
\quad\end{array}$ & 45 & 43 & 40 & 128 \\
$\quad$ \% within the group & $90.0 \%$ & $86.0 \%$ & $80.0 \%$ & $85.3 \%$ \\
CS: & & & & \\
$\quad$ Count & 5 & 7 & 10 & 22 \\
$\quad \%$ within the group & $10.0 \%$ & $14.0 \%$ & $20.0 \%$ & $14.7 \%$ \\
\hline CS: Cesarean Section. & & & & \\
\end{tabular}

Table (4): Indications of cesarean section in the study groups.

\begin{tabular}{llll}
\hline & $\begin{array}{c}\text { Group I } \\
(\mathrm{n}=50)\end{array}$ & $\begin{array}{c}\text { Group II } \\
(\mathrm{n}=50)\end{array}$ & $\begin{array}{c}\text { Control } \\
(\mathrm{n}=50)\end{array}$ \\
\hline Failure of progress & $2(40.0 \%)$ & $4(57.1 \%)$ & $5(50.0 \%)$ \\
Fetal distress & $3(60.0 \%)$ & $2(28.6 \%)$ & $3(30.0 \%)$ \\
Obstructed labour & $0(0.0 \%)$ & $1(14.3 \%)$ & $2(20.0 \%)$ \\
\hline
\end{tabular}

\section{Discussion}

The present study showed that the administration of dexamethasone alone or in combination with the hyoscine butylbomide significantly shortened the interval from the initiation of labor to the start of the active phase, it also decreased the duration of the active phase, the duration of the 2 nd stage and 3 rd stages in comparison to the control group ( $p$-value $<0.001$ for all). In addition, combination therapy caused further shortening of the third stage of labour compared to administering dexamethasone alone $(p=0.043)$.

As regards the effect of intramascular administration of dexamethasone on the duration of labor, our findings are in agreement with those of Kashanian et al., who reported that IM dexamethasone (8mg) injection 6 hours before IOL significantly shortens both the time interval between IOL initiation and the active phase of labour commencement (3.09 \pm 1.5 hours vs. $4.21 \pm 1.8$ hours in control group; $p=0.001) \&$ the duration of the 2 nd stage (22.23 \pm 16.09 minutes vs. $29.01 \pm 15.32$ minutes; $p=0.0014$ ) [13]. Similarly Ziaei et al., declared that using dexamethasone injections results in a notable decrease in the duration of the latent phase of labour ( $1.7 \pm 1.5$ hours vs. $4 \pm 1.7$ hours in control group; $p=0.001$ ), however, they failed to demonstrate any impact of dexamethasone on the duration of the second and third stages of labour [14]. This difference from our results may be due to difference in the number of patients enrolled in their study ( 55 women), as well as the different protocol regarding the dosage and frequency of dexamethasone injections; they used $10 \mathrm{mg}$ of dexamethasone in two doses 12 hours apart and started the induction with intravenous oxytocin on the next day. Kashanian et al., also studied the impact of extra-amniotic saline infusion in combination with dexamethasone for IOL [6]. The authors concluded that adding dexamethasone to extra-amniotic saline infusion would shorten the time interval between IOL \& delivery $(7.25 \pm 2.86 \mathrm{~h}$ vs. 9.763 .91 in the saline only group).

On the otherhand, Kavanagh et al., reviewed a clinical trial conducted on 66 pregnant women in which the effects of prescribing IM dexamethasone together with oxytocin were compared with the effects of using oxytocin alone in IOL [4]. They claimed that corticosteroids were not effective in inducing labour and that this method of induction warranted further research. The difference in results may be justified by the limited number of participants.

Several studies introduced hyoscine butylbromide (Buscopan) as an adjuvant to shorten the duration of labour using different protocols that vary in the route of administration (e.g., IM, IV or rectal suppository) \& doses 20 or $40 \mathrm{mg}$ [3,15-18] In the present study, the IM administration of 40 $\mathrm{mg}$ of HBB in Group B, showed a significant decrease in the duration of the active phase as well as the duration of the second and third stages of labour in comparison to the control group.

Our results are in agreement with Sekhavat et al., who reported that the IV administration of 20mg HBB significantly shortens the duration of both the first stage of labour (187 minutes vs. 260 minutes in placebo group) $\&$ the second stage of 
labour (20 minutes vs. 25 minutes in placebo group) [3]. The same was reported by Kirim et al., (191.1 \pm 43.06min vs. $248.2 \pm 66.1$ in placebo group) and Samuels et al., (156 minutes vs. 228 minutes in placebo group) who both showed an effect on the first stage of labour, but with no impact on the duration of second and third stages of labour $[\mathbf{1 5 , 1 6}$. Additionally, Qahtani and Hajeri claimed the same results but they used 40mg of HBB intramuscularly (165 minutes vs. 215 minutes in placebo group) [17]. Moreover, Makvandi et al., \& Sirohiwal et al., declared that HBB suppositories also significantly reduce the duration of the first stage of labour (141.0 \pm 81.7 minutes vs. $230.1 \pm 169.6$ minutes in the control group \& $123.9 \pm 68.9$ minutes vs. $368.1 \pm 133.0$ minutes in control group, respectively) [18] .

Recently, a Cochrane meta-analysis (17 trials, $n=2617$ ) done by Rohwer et al., reported lowquality evidence that antispasmodics shorten the duration of the first stage of labour by an average of 74.34 minutes with no impact on the duration of the second and the third stages of labour [19] They also demonstrated very low-quality evidence that antispasmodics shorten the whole duration of labour by an average of 85.51 minutes.

On the contrary, Gupta et al. found no statistically significant difference between the HBB group and the control groups as regards the active phase of labour duration and the rate of cervical dilatation [20]. The combination of both dexamethasone and $\mathrm{HBB}$ in IOL, in the present study, may justify the difference in results.

Similar to our results, all previously mentioned studies denied any adverse maternal, foetal or neonatal adverse effects.

The main limitation in the present study was that we included only healthy primigravidas with singleton pregnancies. We excluded complicated pregnancies, previous uterine scar, twin pregnancies and growth-restricted foetuses. In addition, the impact of dexamethasone and HBB was not assessed in the presence of epidural analgesia, which warrants further investigation in the future, and the effect of HBB was not assessed alone without dexamethasone.

To the best of our knowledge, this is the first study that assessed the efficacy of the combined use of dexamethasone and HBB on accelerating induced labour. We believe that any intervention that can safely shorten the painful process of parturition will be greatly appreciated by the patient and any such intervention will also reduce the total required dose of systemic opioid analgesia (which is associated with neonatal respiratory depression) particularly in regions where epidural analgesia is not widely available. Furthermore, shortening the duration of the first stage of labour minimizes undue depletion of the feto-placental reserves, with consequent signs of foetal distress, failed IOL and increased caesarean delivery rate, particularly in women with borderline placental reserve, subjectively reduced liquor amnii, or post-term pregnancies who are usually the target patients for IOL.

\section{Conclusion:}

Intramuscular administration of dexamethasone alone or in addition to HBB was found to shorten the duration of induced labour in primigravidas, with no observed maternal or neonatal complications.

\section{References}

1- MARTIN J., HAMILTON B., VENTURA S., et al.: Births: Final data 2011. Natl. Vital. Stat. Rep., 62 (1), 1, 2013.

2- American Collage of Obstetricians and Gynacologists: Induction of labour. Practice Bulletin No. 107, August 2009, Reaffirmed 2013b.

3- SEKHAVAT L., KARBASI S., FALLAH R. and MIROWLIAI M.: The effect of hyoscine butylbromide first stage of labour in multiparous women Afr. Health Sci., 12: 408-11, 2012.

4- KAVANAGH J., KELLY A.J. and THOMAS J.: Corticosteroids for cervical ripening and induction of labor. Cochrane Database Syst. Rev., (2): CD003100.pub2, 2006.

5- HOFFMAN B., SCHORGE J., SCHAFFER J., et al.: editors. Williams obstetrics. 23 rd ed. New York: MacGrawhill Books, p. 96-122, 2012.

6- KASHANIAN M., FEKRAT M., NAGHASH S. and ANSARI N.: Evaluation of the effect of extraamniotic normal saline infusion alone or in combination with dexamethasone for the induction of labour. J. Obstet. Gynaecol. Res., 34; 47-50. Doi: 10.1111/j.1447-0756. 2007.00703.x, 2008.

7- BARKAI G., COHEN S.B., KEES S., et al.: Induction of labor with use of a foley catheter and extra-amniotic corticosteroids. Am. J. Obstet. Gynecol., 177 (5): 1145 8, 1997.

8- LEVY R., FERBER A., BEN-ARIE A., et al.: A randomized comparison of early versus late amniotomy following cervical ripening with a foley catheter. B.J.O.G., 109 (2): 168-72, 2002.

9- HOT WANI J. and AINAPURE S.S.: Hyoscine butylbromide suppositories. Indian Medical Gaz., 217-9, 2000.

10- CORSEN G.: A study of the use and mode of action of the antispasmodic drug Buscopan in gynecology and obstetrics. Med. Klin., 48: 2186-8, 1983.

11- Thromson-micromedex, anticholinergic antispasmodic; drugs, information for health care professional, 24 edition. Volume 1: 236-7, 2004. 
12- GERALDINE O. SULLIVAN: Analgesia and anaesthesia in labour. Current Obstetrics and Gynecology, 15: 9-17, 2005.

13- KASHANIAN M., DADKHAH F. and MOKHTARI F.: Effect of intramuscular administration of dexamethasone on the duration of labor. Int. J. Gynaecol. Obstet. Off. Organ. Int. Fed. Gynaecol. Obstet., 102: 259-62. Doi: 10.1016/j.ijgo.2008.04.009, 2008.

14- ZIAEI S., ROSEBEHANI N., KAZEMINEJAD A. and ZAFARGHANDI S.: The effects of intramuscular administration of corticostriods on the induction of parturition. J. Perinat. Med., 31 (2): 134-9, 2003.

15- KIRIM S., ASICIOGLU O., YENIGUL N., AYDOGAN B., BAHAT N. and BAYRAK M.: Effect of intravenous hyoscine-N-butyl bromide on active phase of labor progress: A randomized double blind placebo controlled trial. J. Matern.-Fetal Neonatal. Med. Off. J. Eur. Assoc. Perinat. Med. Fed. Asia. Ocean. Perinat. Soc. Int. Soc. Perinat. Obstet., 28: 1038-42. Doi: 10.3109/14767058. 2014.942628, 2015.

16- SAMUELS L.A., CHRISTIE L., ROBERTS-GITTENS B., FLETCHER H. and FREDERICK J.: The effect of hyoscine butylbromide on the first stage of labour in term pregnancies. B.J.O.G. Int. J. Obstet. Gynaecol., 114:15426. Doi: 10.1111/j.1471-0528.2007.01497.x, 2007.

17- QAHTANI N.H.A. and HAJERI F.A.: The effect of hyoscine butylbromide in shortening the first stage of labor: A double blind, randomized, controlled, clinical trial. Ther. Clin. Risk Manag., 7: 495-500. Doi:10.2147/ TCRM.S16415, 2011.

18- MAKVANDI S., TADAYON M. and ABBASPOUR M.: Effect of hyoscine-N-butyl bromide rectal suppository on labor progress in primigravid women: Randomized double-blind placebo-controlled clinical trial. Croat. Med. J., 52: 159-63, 2011.

19- ROHWER A.C., KHONDOWE O. and YOUNG T.: Antispasmodics for labour. Cochrane Database Syst. Rev., CD009243. doi:10.1002/14651858.CD009243.pub3, 2003.

20- GUPTA B., NELLORE V. and MITTAL S.: Drotaverine hydrochloride versus hyoscine-N-butylbromide in augmentation of labor. Int. J. Gynaecol. Obstet. Off. Organ. Int. Fed. Gynaecol. Obstet., 100: 244-7. doi:10.1016/j.ijgo. 2007.08.020, 2008

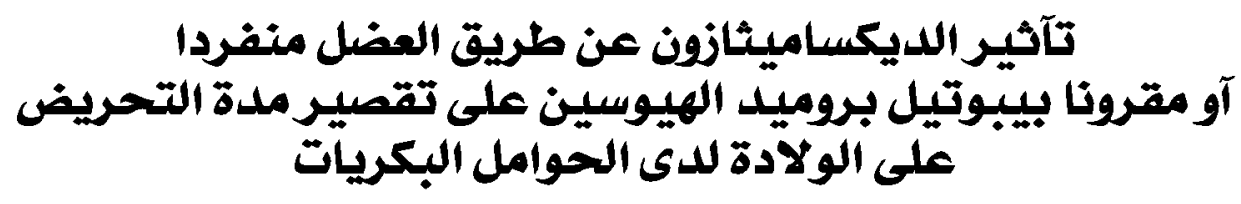

الهدف: تقييم تآثير الديكساميثازون عن طريق العضل منفردا آو مقرونا بييوتيل بروميد الهيوسين على تقصير مدة التصريض على الولادة لدى الحوامل البكريات.

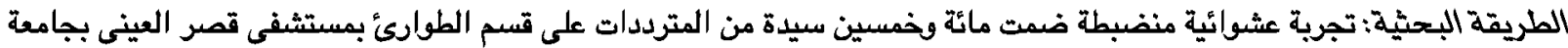

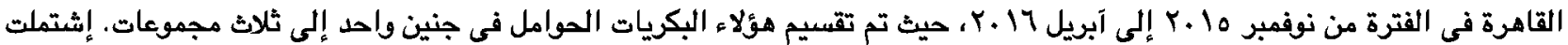

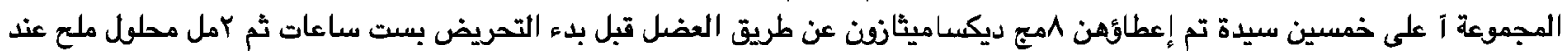

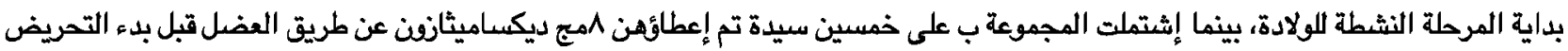

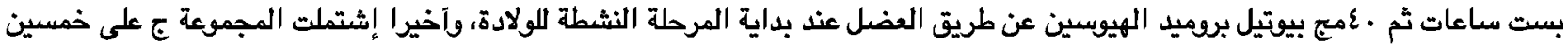

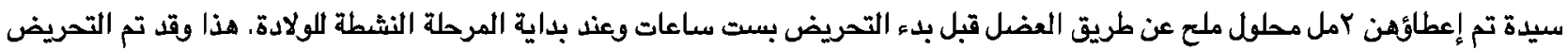

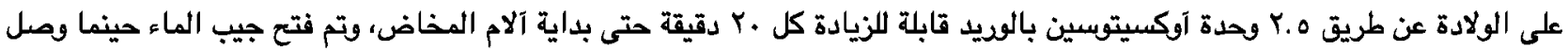

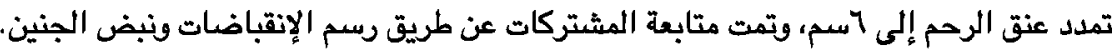

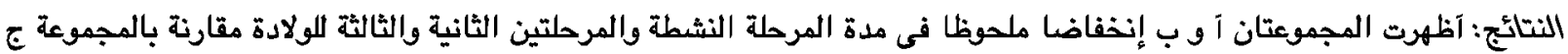

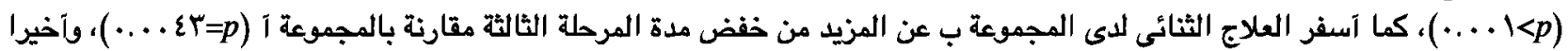

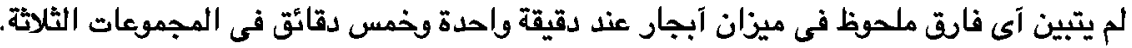

الإستتاج: الديكساميثازن عن طريق العضل منفردا آو مقرونا بيوتيل بروميد الهيوبسين يقصر مدة التصريض على الولادة لدى الحقامل البكريات بدون مضاعفات لدى الآمهات آو الآجنة. 